\title{
Quantitative Femtosecond Laser Atom Probe Analysis of Rare Earth Magnets
}

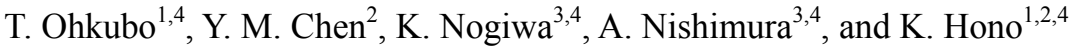 \\ ${ }^{1}$ National Institute for Materials Science, 1-2-1 Sengen, Tsukuba 305-0047, Japan \\ ${ }^{2}$ University of Tsukuba, 1-2-1 Sengen, Tsukuba 305-0047, Japan \\ ${ }^{3}$ Japan Atomic Energy Agency, 8-1 Umebidai, Kizugawa, Kyoto 619-0215, Japan \\ ${ }^{4}$ CREST-JST, Japan
}

There is increasing interest in the quantitative analysis of the grain boundary chemistry of rare earth sintered magnets due to the revived research activity in the development of high coercivity permanent for hybrid and electric vehicles [1]. Using the conventional atom probe, it was totally impossible to acquire atom probe data from the grain boundaries. However, since laser-assisted field evaporation substantially decreases the frequency of specimen rupture [2], it became possible to obtain atom probe data from the grain boundaries of sintered magnets. To obtain useful information of the grain boundary and interfacial chemistry, high mass resolution was required since peaks of $\mathrm{Fe}^{2+}, \mathrm{Co}^{2+}$ and $\mathrm{Cu}^{2+}$ needed to be separated from each other. However, the mass resolution obtained by the straight type laser assisted atom probe often varied with different specimen preparation condition and different measurement condition. In this work, we investigated optimal pulsed laser conditions (wave length and pulse power) to obtain highest mass resolution with high signal to noise ratio $(\mathrm{S} / \mathrm{N})$. A 400 -fs pulsed laser system was operated at $2 \mathrm{kHz}$ to assist field evaporation under a standing DC voltage ranging from 13.0-14.9 kV. Mass spectra obtained by the laser pulses with two different wavelengths, $1030 \mathrm{~nm}$ (IR) and $515 \mathrm{~nm}$ (Green) were compared. All the measurements were carried out on the same tip at $50 \mathrm{~K}$ with evaporation rate of 0.02-0.04 ion/pulse.

Figure 1 shows $\mathrm{Cu}$ atom map obtained from a $\mathrm{Sm}(\mathrm{Co}, \mathrm{Cu}, \mathrm{Zr}, \mathrm{Fe})_{7.4}$ sintered magnet with $515 \mathrm{~nm}$ wavelength and $0.27 \mu \mathrm{J} /$ pulse laser energy. Also, the mass spectra obtained from the magnet with various laser powers of two different wave lengths are shown in Fig. 2. Each spectrum consists of 600,000 atoms. Using $1030 \mathrm{~nm}$ wavelength laser with the polarization parallel to the specimen axis, the background noise and required DC voltage generally decreased as the laser energy was increased from 1.76 to $3.25 \mu \mathrm{J} /$ pulse. With higher laser energy, lower DC standing voltage is required to maintain the same evaporation rate [3], thereby decreasing the background noise. Using $515 \mathrm{~nm}$ wavelength laser, despite the energy was as low as $0.27 \mu \mathrm{J} /$ pulse, it allowed the lowest background noise. This is probably due to the higher absorption coefficient of metals for the shorter wavelength [4]. The mass resolution, $\mathrm{S} / \mathrm{N}$ ratio, and the composition of the alloy determined from the 600,000 atoms are shown in Table. 1. Systematic studies on Nd-Fe-B magnets also showed similar tendency. We will discuss the mass-resolution influenced by the acceleration voltage of the $\mathrm{Ga}^{+}$of FIB micro fabrication. By optimizing these parameters, quantitative analysis results from both $\mathrm{Sm}(\mathrm{Co}, \mathrm{Cu}, \mathrm{Zr}, \mathrm{Fe})_{7.4}$ and $\mathrm{Nd}-\mathrm{Fe}-\mathrm{B}$ sintered magnets were obtained.

\section{References}

[1] W. F. Li et al., Appl. Phys. Lett. 93, (2008) 082505.

[2] G. L. Kellogg et al., J. Appl. Phys. 51(2) (1980) 1184

[3] G. L. Kellogg, J. Appl. Phys. 52 (1981) 5320.

[4] Handbook of Optical Constants of Solids. edited by Edward D. Palik, Academic Pr, 1985. 


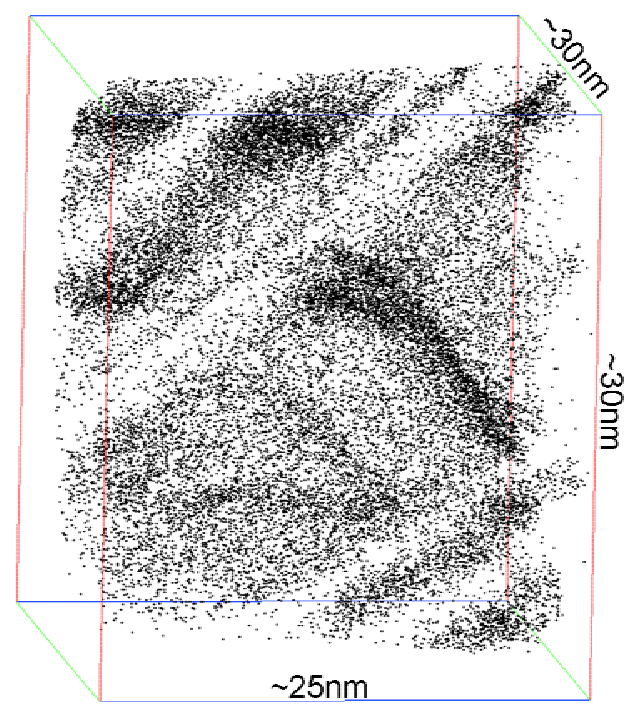

Fig. 1. $\mathrm{Cu}$ atom map in $\mathrm{Sm}(\mathrm{Co}, \mathrm{Cu}, \mathrm{Zr}, \mathrm{Fe})_{7.4}$ sintered magnet. Wavelength $=515 \mathrm{~nm}$, laser energy $=0.27 \mu \mathrm{J} /$ pulse.

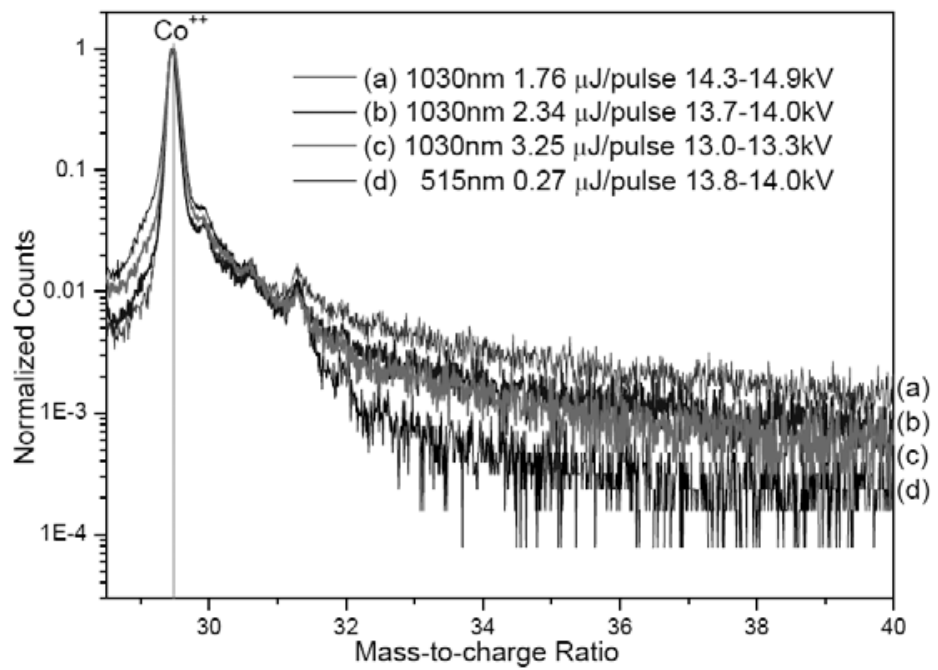

Fig. 2. The effect of laser power and wavelength on background noise in $\mathrm{Sm}(\mathrm{Co}, \mathrm{Cu}, \mathrm{Zr}, \mathrm{Fe})_{7.4}$ sintered magnet.

TABLE 1 . The mass resolution, $\mathrm{S} / \mathrm{N}$ ratio, and the alloy composition.

\begin{tabular}{cccc}
\hline Laser condition & $\begin{array}{c}\text { Mass resolution: } \mathrm{m} / \Delta \mathrm{m} \\
\text { HWHM of }{ }^{59} \mathrm{Co}^{++}\end{array}$ & $\mathrm{S} / \mathrm{N}$ ratio* & $\begin{array}{c}\text { Alloy composition } \\
\text { Nominal composition: } \\
\mathrm{Sm}_{11.8} \mathrm{Co}_{63.5} \mathrm{Fe}_{17.6} \mathrm{Cu}_{4.9} \mathrm{Zr}_{2.2}\end{array}$ \\
\hline $1030 \mathrm{~nm}, 1.76 \mu \mathrm{J} /$ pulse & 226 & 10.2 & $\mathrm{Sm}_{15.3} \mathrm{Co}_{67.5} \mathrm{Fe}_{9.3} \mathrm{Cu}_{5.6} \mathrm{Zr}_{2.2}$ \\
$1030 \mathrm{~nm}, 2.34 \mu \mathrm{J} / \mathrm{pulse}$ & 245 & 18.2 & $\mathrm{Sm}_{15.3} \mathrm{Co}_{67.4} \mathrm{Fe}_{9.7} \mathrm{Cu}_{5.5} \mathrm{Zr}_{2.1}$ \\
$1030 \mathrm{~nm}, 3.25 \mu \mathrm{J} / \mathrm{pulse}$ & 268 & 29.5 & $\mathrm{Sm}_{14.9} \mathrm{Co}_{67.0} \mathrm{Fe}_{11.3} \mathrm{Cu}_{5.3} \mathrm{Zr}_{1.5}$ \\
$515 \mathrm{~nm}, 0.27 \mu \mathrm{J} / \mathrm{pulse}$ & 295 & 90.2 & $\mathrm{Sm}_{14.0} \mathrm{Co}_{67.9} \mathrm{Fe}_{11.0} \mathrm{Cu}_{5.9} \mathrm{Zr}_{1.2}$ \\
\hline
\end{tabular}

* Detected number of ions in 29-30 and 34-44 were counted as a signal and noise, respectively. 